\title{
Flutuação populacional de esporângios de Peronospora destructor no ar e sua relação com a severidade do míldio da cebola
}

\author{
Leandro Luiz Marcuzzo ${ }^{1}$, Maíra Rodrigues Duffeck ${ }^{1,2}$
}

${ }^{1}$ Instituto Federal Catarinense - IFC/Campus Rio do Sul, CP 441, CEP 89.163-356, Rio do Sul, SC; ${ }^{2}$ Aluna do curso de Agronomia e Bolsista PIBITI/CNPq - IFC/Campus Rio do Sul, mairarodrigues.16@gmail.com

Autor para correspondência: Leandro Luiz Marcuzzo (marcuzzo@ifc-riodosul.edu.br)

Data de chegada: 10/03/2014. Aceito para publicação em: 19/01/2015.

$10.1590 / 0100-5405 / 1984$

\section{RESUMO}

Marcuzzo, L.L.; Duffeck, M.R. Flutuação populacional de esporângios de Peronospora destructor no ar e sua relação com severidade do míldio da cebola. Summa Phytopathologica, v.41, n.1, p.68-70, 2015.

Em experimento de campo nos anos de 2011, 2012 e 2013 quantificou-se a flutuação de esporângios de Peronospora destructor e sua relação com a severidade de míldio em cebola. Mudas de cebola do cultivar Bola Precoce foram transplantadas em quatro repetições de 60 plantas. Os esporângios foram coletados através de um coletor de esporos tipo "cata-vento", contendo uma lâmina de microscópio untada com vaselina, a qual era quantificada semanalmente com auxílio de microscópio. A severidade da doença foi analisada através da porcentagem de área foliar afetada pela doença. O número de esporângios e a severidade do míldio da cebola foram submetidos ao cálculo do coeficiente de correlação linear de Pearson (r). Nos anos de 2011 e 2012 a coleta de esporângios ocorreu posteriormente à constatação da doença, provavelmente devido haver baixo inóculo no ar. Já no ano de 2013 a coleta de esporângios ocorreu anteriormente à ocorrência da doença, porém de forma esporádica e em pequena quantidade, presupondo que esses estavam no ar e foram capturados pelo coletor. A correlação entre as variáveis flutuações de esporângios e a severidade da doença foi significativa, $r=0,90, r=0,94$ e r=0,80; para os anos de 2011, 2012 e 2013 respectivamente. A severidade da doença em cebola é influenciada pela presença dos esporângios coletadas do ar.

Palavras-chave adicionais: Allium cepa, aerobiologia, míldio.

\section{ABSTRACT}

Marcuzzo, L.L.; Duffeck, M.R. Population fluctuation of Peronospora destructor sporangia in the air and its relationship with the severity of onion downy mildew. Summa Phytopathologica, v.41, n.1, p.68-70, 2015.

In a field trial in the years of 2011, 2012 and 2013, the fluctuation of Peronospora destructor sporangia and its relationship with the severity of downy mildew in onions were quantified. Seedlings of onion cultivar Bola Precoce were transplanted into four replicates of 60 plants. Sporangia were collected by means of a "vane"-type spore collector containing a microscopic slide smeared with vaseline and were weekly quantified by using a microscope. The severity of the disease was analyzed based on the percentage of leaf area affected by the disease. The number of sporangia and the severity of downy mildew in onion were subjected to the calculation of Pearson's correlation coefficient (r). In 2011 and 2012, the collection of sporangia occurred after the observation of the disease probably because the inoculum concentration in the air was low. However, in 2013, sporangium collection occurred before the disease observation but sporadically and at small quantities, suggesting that those sporangia were already present in the air and were captured by the collector. The correlation between the variables sporangium fluctuation and disease severity was significant, $\mathrm{r}=0.90, \mathrm{r}=0.94$, and $\mathrm{r}=0.80$ for 2011,2012 and 2013 , respectively. The severity of the disease in onions is influenced by the presence of sporangia collected from the air.

Additional keywords: Allium cepa, aerobiology, downy mildew.

Dentre as doenças foliares que atacam a cultura da cebola e reduzem o seu potencial produtivo, destaca-se o míldio causado por Peronospora destructor (2). Atualmente não há cultivares resistentes a esta doença, e, por isso, o seu controle vem sendo feito com pulverizações frequentes de fungicidas protetores e sistêmicos (10). Uma das maneiras de reduzir o uso de agrotóxicos é conhecer quais as condições que favorecem a ocorrência da doença, que envolvem o ambiente, o patógeno e o hospedeiro (1). Em relação ao patógeno, o detalhamento da dispersão anemófila de esporângios do míldio no ar em área de cultivo constitui-se em uma informação de relevância no avanço do manejo fitossanitário $(3,8)$. Diante do exposto, este trabalho teve por objetivo avaliar a flutuação de esporângios de $P$. destructor no ar em área de cultivo de cebola e sua relação com severidade do míldio da cebola nos anos de 2011, 2012 e 2013.

O experimento foi realizado de julho a novembro nos anos de 2011, 2012 e 2013, no Instituto Federal Catarinense, Campus de Rio do Sul, município de Rio do Sul/SC com latitude Sul de $27^{\circ} 11^{\prime}$ '07', longitude Oeste de 49³9'39" e altitude de 687 metros do nível do mar.

Mudas de cebola da cultivar Bola Precoce foram transplantadas a campo em quatro repetições constituídas de uma área de $1,5 \mathrm{~m}$ X 1,5m cada. Cada repetição continha 60 plantas e 10 dessas foram previamente demarcadas de forma aleatória para a avaliação da severidade da doença. A calagem, adubação e tratos culturais seguiram as normas recomendadas para a cultura (4), porém não foi utilizado fungicida. $\mathrm{O}$ 
ciclo da cultura nos três anos de avaliação foi variável, sendo 13, 16 e 18 semanas respectivamente para os anos de 2011, 2012 e 2013. Esta variação foi devido à precipitação pluviométrica no final de cultivo e o percentual de plantas estaladas.

A coleta dos esporângios de $P$. destructor no ar foi realizada através de um coletor de esporos tipo "cata-vento" (9), posicionado a 0,4 metros de altura, localizado no centro do experimento. No interior do coletor havia uma lâmina de microscópio $(7,5 \times 2,5 \mathrm{~cm})$ untada com vaselina a qual era substituída semanalmente. Em laboratório, a lâmina foi dividida em dois pontos centrais e adicionou-se 2 gotas de azul de Amann e sobre estas foram depositadas lamínulas $(1,8 \times 1,8 \mathrm{~cm})$. Através da visualização em microscópio ótico com a objetiva de 10 vezes quantificou-se o número de esporângios coletados semanalmente. A severidade da doença foi analisada através da porcentagem de área foliar afetada pela doença em cada folha exposta. Para verificar a relação entre a flutuação de esporângios e a severidade do míldio da cebola durante o ciclo da cultura, os dados foram submetidos ao cálculo do coeficiente de correlação linear de Pearson (r) e sua significância foi verificada pelo teste $\mathrm{T}$.

Nos três anos de avaliação a correlação de Pearson (r) entre o número de esporângios coletados do ar e a severidade da doença foi significativa pelo teste de T a 1\% (Tabela 1).

A coleta de esporângios nos anos de 2011 e 2012 ocorreu posteriormente à constatação da doença a campo (Tabela 1). Hildebrand \& Sutton (5) também coletaram esporângios do míldio da cebola após ocorrer a esporulação em plantas doentes, similar com a ferrugem asiática da soja (6). Já no ano de 2013, a coleta de esporângios ocorreu três semanas antes da constatação da doença (Tabela 1).

Após a nona semana do aparecimento da doença no ano de 2011, observou-se um acréscimo gradual de severidade e paralelamente ocorreu um aumento de esporângios coletados, com exceção da última semana antes da colheita dos bulbos. Isso pode ser associado ao fato de que a planta já se encontrava em processo de senescência e também a grande taxa de infecção do míldio, o que resultou na diminuição do número de esporos. A correlação entre os dados da severidade da doença e do número de esporos coletados foi significativa, $r=0,90$, (Tabela 1) indicando alta linearidade entre estas duas variáveis.

No ano de 2012, a doença foi observada na oitava semana após o transplantio (SAT) das mudas, apesar de ter sido coletado esporos apenas na décima SAT (Tabela 1). No entanto, apesar de pouco variável o número de esporângios entre a $8^{\mathrm{a}}$ e $10^{\mathrm{a}} \mathrm{SAT}$, verificou-se que a severidade da doença progrediu lentamente até a décima primeira semana. Os esporângios foram coletados somente a partir da décima semana, com pouca variação entre a $14^{\mathrm{a}}$ e $16^{\mathrm{a}}$ semana, porém a doença foi gradativa durante esse período. A correlação entre a flutuação de esporângios e a severidade da doença no ano de 2012 foi significativa $(\mathrm{r}=0,94)$ (Tabela 1).

Em 2013 ocorreu a coleta de alguns esporângios antes do aparecimento da doença. Porém, a flutuação de esporângios seguiu o mesmo comportamento de 2011. Neste ano o aumento da severidade da doença, embora em baixa proporção, comparado aos anos anteriores houve também o incremento no número de esporângios quantificados. Mesmo com baixa severidade $(<0,9 \%)$ houve uma correlação entre o número de esporângios coletados e a doença altamente significativo $(\mathrm{r}=0,80)$ (Tabela 1$)$.

Keske (7) avaliando a flutuação de Monilia fructicola, agente causal da podridão parda do pessegueiro coletados em armadilhas do tipo "cata-vento", observou que foi constante a coleta durante o período vegetativo da cultura, não ocorrendo capturas apenas no período da pré-colheita, apesar de haver alta incidência da doença durante esse período. Isso evidência que o inóculo presente no ambiente serve de um indicativo para a ocorrência da doença, como ocorre em sistema

Tabela 1. Coeficiente de correlação (r) entre o número de esporângios de Peronospora destructor coletados semanalmente após o transplante de mudas e as respectivas severidades do míldio no ciclo da cultura da cebola (cv. Bola Precoce) nos anos de 2011, 2012 e 2013. IFC, Campus de Rio do Sul, SC

\begin{tabular}{|c|c|c|c|c|c|c|}
\hline \multirow{2}{*}{$\begin{array}{c}\text { Semanas após o } \\
\text { transplante }\end{array}$} & $\begin{array}{c}\mathrm{N}^{\circ} \text { de } \\
\text { esporângios }\end{array}$ & $\begin{array}{c}\text { Severidade } \\
(\%)\end{array}$ & $\begin{array}{c}\mathrm{N}^{\circ} \text { de } \\
\text { esporângios }\end{array}$ & $\begin{array}{c}\text { Severidade } \\
(\%)\end{array}$ & $\begin{array}{c}\mathrm{N}^{\circ} \mathrm{de} \\
\text { esporângios }\end{array}$ & $\begin{array}{c}\text { Severidade } \\
(\%)\end{array}$ \\
\hline & \multicolumn{2}{|c|}{2011} & \multicolumn{2}{|c|}{2012} & \multicolumn{2}{|c|}{2013} \\
\hline 1 & 0 & 0 & 0 & 0 & 0 & 0 \\
\hline 2 & 0 & 0 & 0 & 0 & 0 & 0 \\
\hline 3 & 0 & 0 & 0 & 0 & 0 & 0 \\
\hline 4 & 0 & 0 & 0 & 0 & 0 & 0 \\
\hline 5 & 0 & 0 & 0 & 0 & 0 & 0 \\
\hline 6 & 0 & 0 & 0 & 0 & 0 & 0 \\
\hline 7 & 0 & 0 & 0 & 0 & 0 & 0 \\
\hline 8 & 0 & 0 & 0 & 0,4 & 0 & 0 \\
\hline 9 & 0 & 2,1 & 0 & 1,5 & 0 & 0 \\
\hline 10 & 33 & 5,9 & 1 & 2,8 & 0 & 0 \\
\hline 11 & 302 & 19,7 & 1 & 4,7 & 0 & 0 \\
\hline 12 & 438 & 34,4 & 2 & 16,2 & 1 & 0 \\
\hline 13 & 326 & 53,8 & 1 & 21,2 & 1 & 0 \\
\hline 14 & - & - & 4 & 24,7 & 1 & 0 \\
\hline 15 & - & - & 4 & 29,3 & 1 & 0,2 \\
\hline 16 & - & - & 6 & 35,4 & 2 & 0,8 \\
\hline 17 & - & - & - & - & 9 & 0,9 \\
\hline 18 & - & - & - & - & 3 & 0,9 \\
\hline $\begin{array}{l}\text { Coeficiente de } \\
\text { correlação (r) }\end{array}$ & \multicolumn{2}{|c|}{$0,90 *$} & \multicolumn{2}{|c|}{$0,94^{*}$} & \multicolumn{2}{|c|}{$0,80^{*}$} \\
\hline
\end{tabular}

- = não avaliado.

* significativo a $1 \%$ de probabilidade pelo teste T. 
de plantio direto (8).

A presença de esporângios de $P$. destructor é um indicador do aumento da severidade do míldio na cultura da cebola e pode ser usado futuramente como um indicador de controle em um sistema de previsão da doença.

\section{REFERÊNCIAS BIBLIOGRÁFICAS}

1. Bergamim Filho, A. Conceitos e objetivos. In: Bergamim Filho, A.; Kimati, H.; Amorim, L. (Ed.). Manual de fitopatologia: princípios e conceitos. 3. ed. São Paulo: Ceres, 1995. v. 1, cap. 27, p.540-553.

2. Boff, P. Levantamento de doenças na cultura da cebola, em Santa Catarina. Fitopatologia Brasileira, Brasília, DF, v.21, n.2, p.110-114, 1996.

3. Casa, R.T.; Reis, E.M.; Zambolim, L. Dispersão vertical e horizontal de conídios de Stenocarpella macrospora e Stenocarpella maydis. Fitopatologia Brasileira, Brasília, DF, v.29, n.2, p.141-147, 2004.

4. Epagri. Sistema de produção para cebola: Santa Catarina. Florianópolis. 2013, 106p. (Sistemas de Produção, 46).
5. Hildebrand, P.D.; Sutton, J.C. Weather variables in relation to na epidemic of downy mildew. Phytopathology, St. Paul, v.72, n.3, p.219-224, 1982.

6. Juliatti, F.C.; Rezende, A.A.; Vale, F.X.R. Critérios práticos de fundamento epidemiológico que auxiliam na tomada de decisão para o controle de doenças de plantas. Tropical Plant Pathology, Brasília, DF, v.35, p.23-25, 2010. Suplemento.

7. Keske, C. Epidemiologia da podridão parda em pessegueiros conduzidos em sistema de produção orgânico no alto vale do Itajaí - SC. 2009. 119f. Tese (Doutorado em Produção Vegetal) - Universidade Federal do Paraná, Curitiba.

8. Reis, E.M.; Mário, J.L. Quantificação do inóculo de Diplodia macrospora e de D. maydis em restos culturais, no ar, e sua relação com a infecção em grãos de milho. Fitopatologia Brasileira, Brasília, DF, v.28, n.2, p.143147,2003

9. Reis, E.M.; Santos, H.P. População de Helmintosporium sativum no ar quantificado através de uma armadilha tipo cata-vento. Fitopatologia Brasileira, Brasília, DF, v.10, n.5, p.515-519. 1985.

10. Wordell Filho J.A; Martins; Stadnik M.J. Aplicação foliar de tratamentos para o controle do míldio e da podridão-de-escamas de bulbos de cebola. Horticultura Brasileira, Brasília, DF, v.25, n.4, p.544-549, 2007. 